\title{
Verification of ANSYS Fluent and OpenFOAM CFD platforms for prediction of impact flow
}

\author{
Petra Tisovská ${ }^{1}$, Pavel Peukert ${ }^{1}$, Jan Koláŕ $^{1}$ \\ ${ }^{1}$ VÚTS Liberec, a. s., 460001 Liberec XI, Czech Republic
}

\begin{abstract}
The main goal of the article is a verification of the heat transfer coefficient numerically predicted by two CDF platforms - ANSYS-Fluent and OpenFOAM on the problem of impact flows oncoming from 2D nozzle. Various mesh parameters and solver settings were tested under several boundary conditions and compared to known experimental results. The best solver setting, suitable for further optimization of more complex geometry is evaluated.
\end{abstract}

\section{Introduction}

An impact flow is widely used for a very intensive drying effect of wet surfaces. Although it's good performance is generally well known, there are still many geometric parameters to be exploit regarding their influence on drying. CFD simulation of nozzle designs may be accepted as a technically easiest approach to find the most efficient geometry of the nozzle. Unfortunately the fluid mechanics of the impact flow is very complex and demanding to be numerically simulated. Particularly, the prediction of near-wall turbulence parameters of the flow of various regimes along the wall for, is the most obvious problem.

For the examination of the impact flow were used two highly sophisticated CFD packages. The commercial software ANSYS-Fluent 17.1 and open source package OpenFOAM 4.0. Both solvers computed the same flow problems of impact flow oncoming to a normal wall and results are later compared with experimental data.

\section{Investigated task}

For investigation purposes the geometry based on the experimental work of Korger and Křížek [1] was used. They determined averaged local mass transfer coefficients of an impact flow from a slit nozzle. The impact flow is used commonly to increase the heat and mass transfer from the wall (Polat[2], Martin[3]). Because the heat and mass transfer physics in the boundary layer are similar one to the other, like mentioned Ghiaasiaan [4] or Zoot [5], it is possible to find a correlation between them.

The slit nozzle scheme of Korger and Křižek's [1] experiment is shown in the Fig.1. Where b is the nozzle orifice width, alpha the nozzle opening angle, L the height between the nozzle orifice and upper wall and $\mathrm{s}$ the height between the nozzle orifice and affected wall. The dimension $\mathrm{x}$ represents the horizontal coordinate from the centre of the nozzle. The problem is fully twodimensional.

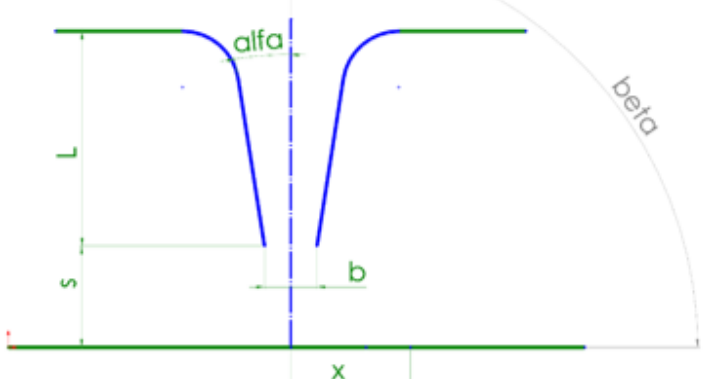

Fig. 1. Scheme of the tested nozzle

The resulting mass transfer coefficients for various parameters from their experiment [1] are shown in the Fig.2. Gaining the maximal total surface heat and mass transfer for a limited minimal wall to nozzle orifice distance the case with the $\mathrm{s} / \mathrm{b}$ ratio of 4 was chosen. Interesting for that case is the presence of two local minimums and two smaller local maximums and a higher total mass transfer coefficient. Which is caused by increased turbulence a resulting mixing at the wall region.

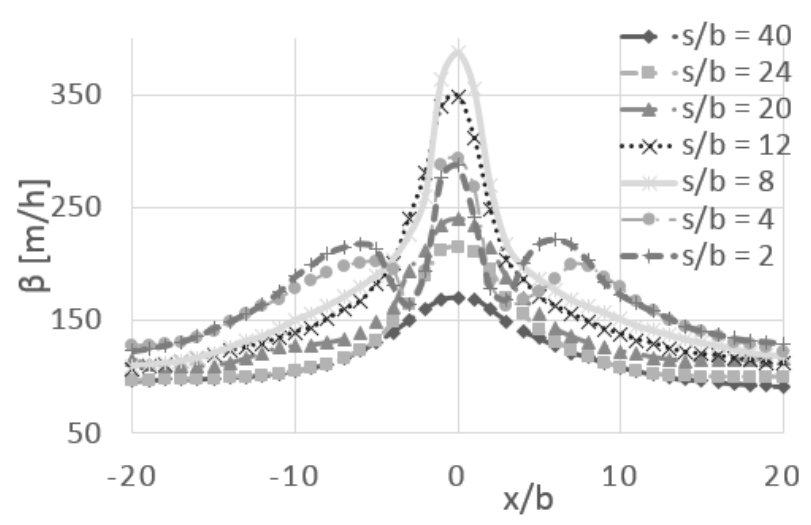

Corresponding author: pavel.peukert@vuts.cz 
Fig. 2. Local mass transfer coefficient from Korger and Křižek's experiment [1].

For the computations was used a $4 \mathrm{~mm}$ nozzle width with an open angle of $7^{\circ}$. The computational grid (Fig.3) was created in Ansys-meshing and was used for all computations presented. The mesh in near-wall and impact regions is refined to ensure proper resolution for the simulation. Because the computations were done within a parametric study only a $2 \mathrm{D}$ computational grid with 150 thousand elements was used.

\section{Computation conditions}

For the Fluent and OpenFOAM the same settings were set where possible. To get the similar conditions to the experiment the pressure at the inlet was set to an overpressure of $480 \mathrm{~Pa}$ which causes an average flow velocity of $30 \mathrm{~m} / \mathrm{s}$ in the nozzle orifice and a temperature of $300 \mathrm{~K}$. The pressure outlet was set to $0 \mathrm{~Pa}$ overpressure and a backflow temperature of $300 \mathrm{~K}$. The wall temperature was set to $320 \mathrm{~K}$ to ensure a reasonable range to use constant air properties for normal pressure of 1 atmosphere and $300 \mathrm{~K}$.

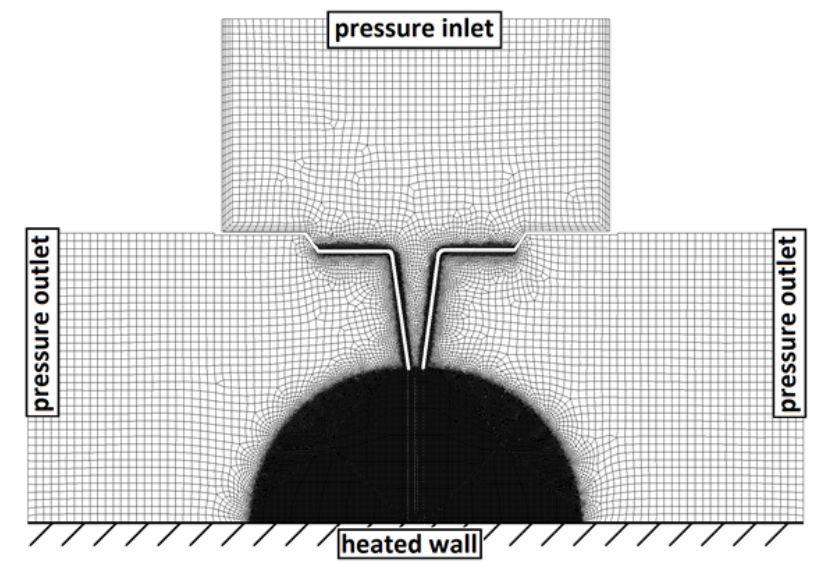

Fig. 3. Unstructured grid used for computations

Considering that the flow had significantly turbulent regions, few k-omega and k-epsilon turbulence models were tested in both program environments, because of their relative unobtrusive computing requirements for engineering computations [7].

\subsection{Used turbulence models}

The models of turbulence (eddy viscosity) had different approach how to handle the turbulence and turbulent energy dissipation. Due the different computation platforms some differences in the setting are present. Still the settings and schemes were try to by similar as possible.

In the both environments the RANS equations were fulfilled with the k-omega standard and SST formulation. Further k-epsilon standard, RNG and Realizable were included. Moreover, the difference of the standard and enhanced wall treatment for resolving the near-wall flow parameters was tested for the kepsilon models in ANSYS-Fluent.

\section{Heat and mass transfer relations}

The boundary-layer conservation equations for momentum, thermal energy and mass species are mathematically similar so an analogy between these three parts was proposed and described in various literature [4], [8]. Due the time the analogy proposes developed from the relative simple Reynolds analogy over few stages to the most accurate Chilton-Colburn Analogy which defines dimensionless $\mathrm{j}$ parameters for heat $\left(j_{\text {th }}\right)$ and mass transfer $\left(j_{\text {ma }}\right)$ which were assumed to be near equal.

$$
\begin{aligned}
& j_{\mathrm{th}}=\frac{\mathrm{Nu}_{\mathrm{l}}}{\mathrm{Re}_{\mathrm{l}} \operatorname{Pr}_{l}^{1 / 3}} \\
& j_{\mathrm{ma}}=\frac{\mathrm{Sh}_{1}}{\mathrm{Re}_{\mathrm{l}} \mathrm{Sc}^{1 / 3}}
\end{aligned}
$$

That assumption provides a tool to estimate the heat flux or mass transfer values if the main flow parameters and one of the mentioned values are known.

The experimental value of the mass transport coefficient was recomputed to dimensionless heat flux $\dot{q}^{*}$ which is defined by equation

$$
\dot{q}^{*}=\dot{q} / \dot{q}_{\mathrm{wam}},
$$

where $\dot{q}$ is the local heat transfer and $\dot{q}_{\text {wam }}$ the weighted averaged mean of the investigated case. The choice to observe heat transfer was done with regard to following research investigations.

\section{Results from ANSYS-Fluent}

From various computations the local heat transfer rates which were converted to dimensionless heat flux using equation 3 were obtained. They were compared to the experiment in Fig.4. The chart shows similar progress with the local minimum in a similar position for the komega standard and SST. While the k-epsilon model tendency is to smoothing the curves. The total heat transfer comparison for the k-epsilon RNG with enhanced wall functions had the best match, while other k-epsilon models overestimate the heat flux. 


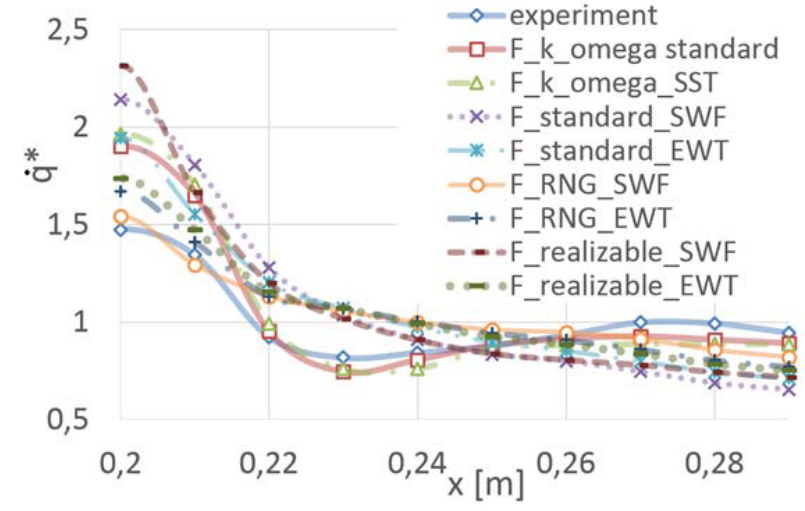

Fig. 4. Chart of dimensionless heat flux on horizontal wall distance from the experiment and Ansys-Fluent simulation

In Fig. 5 the pressure field from ANSYS-Fluent for the k-epsilon model is shown, which has a relative similar shape like the result in Fig.8 from OpenFOAM with small value deflections. The graphic outlay is a little different, because the pictures for the Fluent solutions were post-processed in ANSYS CFD-post and the solution from OpenFOAM were processed in Paraview.

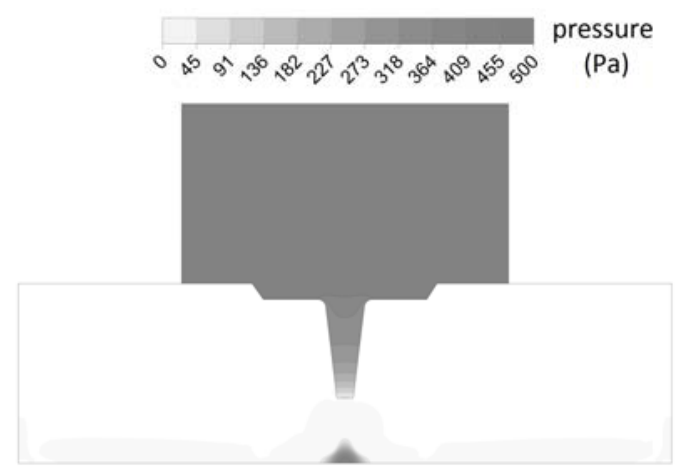

Fig. 5. Pressure field from Ansys-Fluent, k-esilon standard

Fig. 6 shows the velocity field from Ansys-Fluent and Fig. 9 from OpenFOAM. With small value deflections.

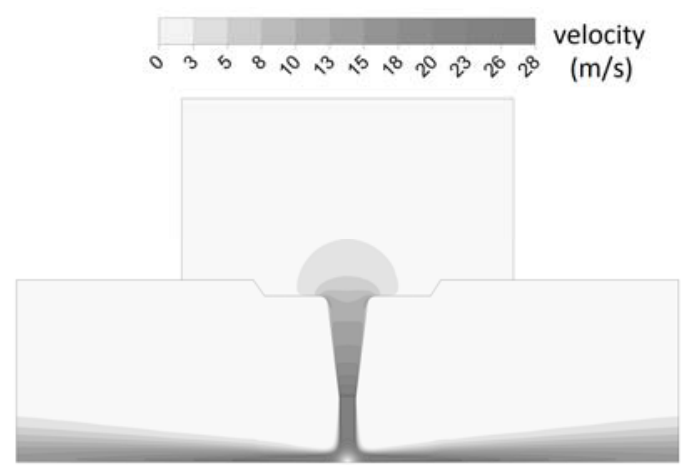

Fig. 6. Velocity magnitude from Ansys-Fluent, k-epsion standard

\section{Results from OpenFOAM}

Local dimensionless heat flux for the OpenFOAM results is shown in Fig.7. The progress curves of the dimensionless heat flux is for all cases similar with a little different tilt. None of them matches the experimental results.

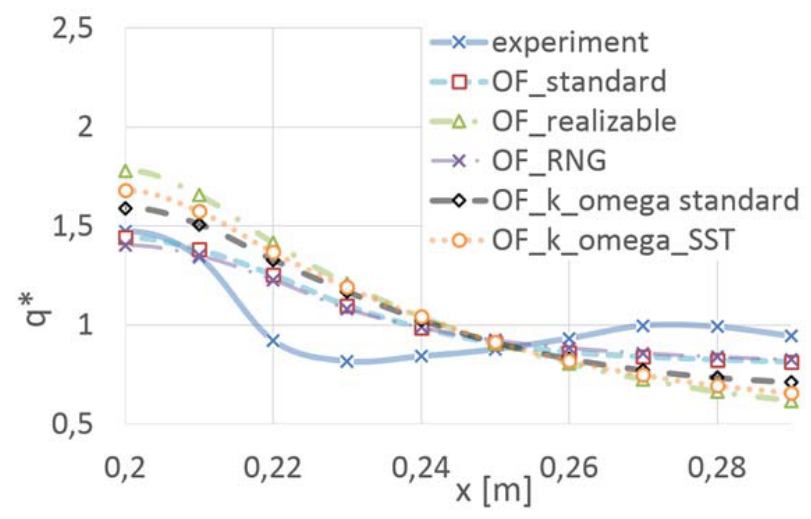

Fig. 7. Chart of dimensionless heat flux on horizontal wall distance from the experiment and OpenFOAM simulation

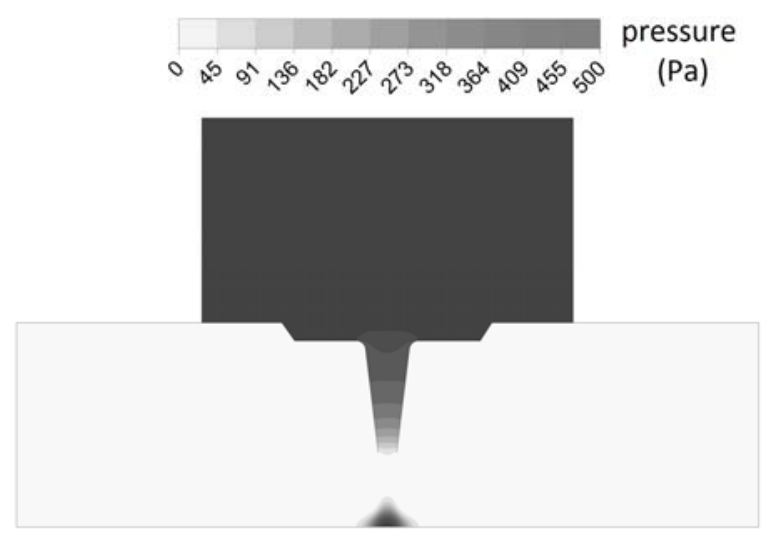

Fig. 8. Pressure field from OpenFOAM, k-epsilon standard
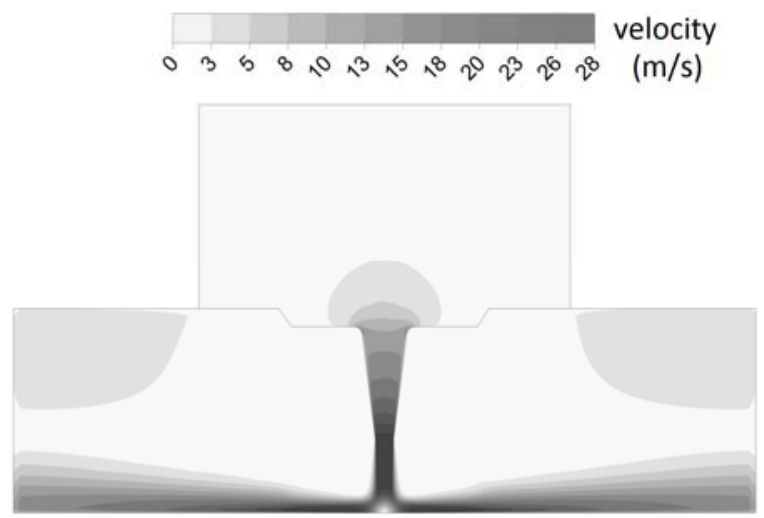

Fig. 9. Velocity field from OpenFOAM, k-epsilon standard

\section{Facing the results from experiment ANSYS-Fluent and OpenFOAM}

The k-omega standard (Fig.10) model in ANSYS-Fluent gives tendency compared to the experiment with an overestimation in the central area and underestimation at local minimums, but the positions of these are relative correct. From OpenFOAM a smooth curve with only one global maximum is the result of solution. The SST modifications (Fig.11) gives similar result like the standard model. A small change at the far-sides where 
the heat flux holds a constant value shows in ANSYSFluent results only.

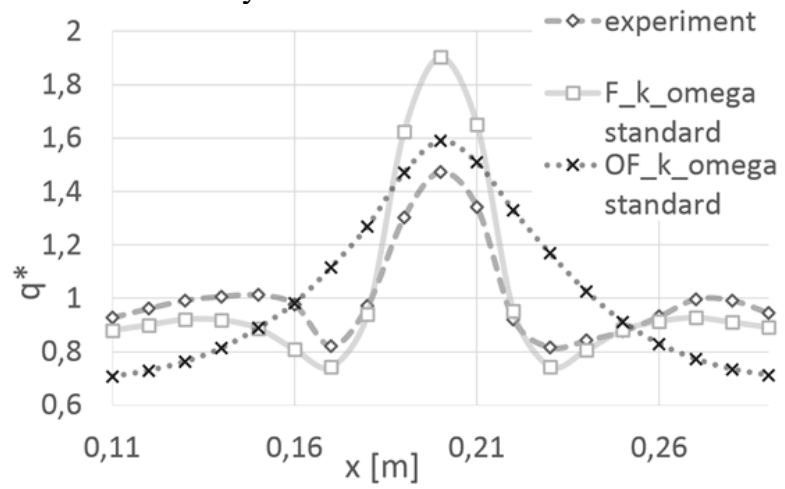

Fig. 10. Dimensionless heat flux for k-omega standard model

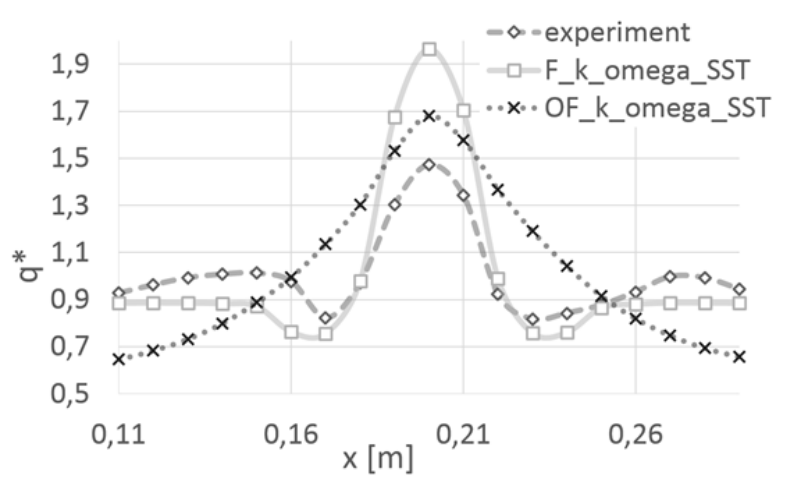

Fig. 11. Dimensionless heat flux for k-omega SST model

All k-epsilon turbulent models smoothed out the local minimums. And even when they had a similar total heat flux of the area like the experiment they were not able to resolve properly the problem. The standard kepsilon (Fig.12) from Ansys-Fluent and OpenFOAM varies especially in the area of the global maximum.

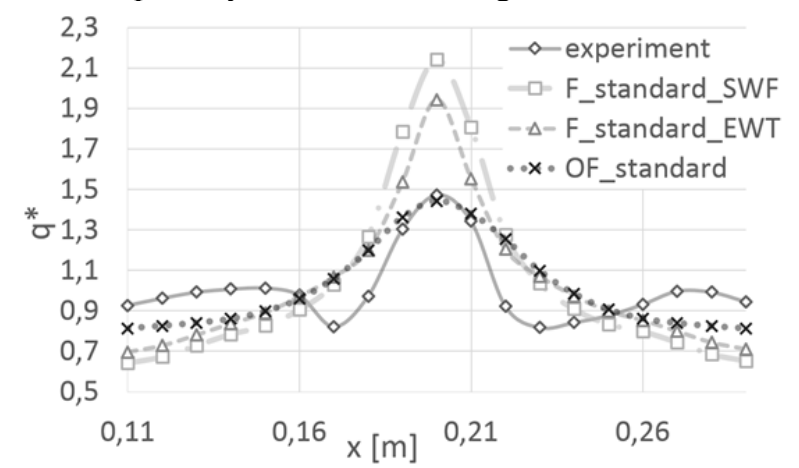

Fig. 12. Dimensionless heat flux for k-epsilon standard

The modified formulations of RNG (Fig.13) and realizable (Fig.14) match between both platforms relatively well. Which allows a possible direct comparison between cases computed with these models on both platforms.

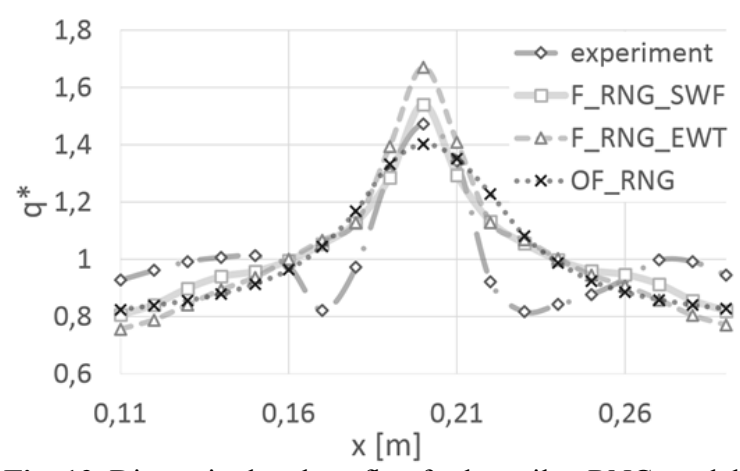

Fig. 13. Dimensionless heat flux for k-epsilon RNG model

\section{Summary}

The considered numerical solutions never get the exactly same shape of the heat transfer coefficient like the one obtained from the conversion from the experiment. That is given partially due to some state of simplification in the analogy between mass and heat transfer rates and the simplifications in the turbulence models (2D modelling, RANS approach, boundary layer regimes). It is not possible to do a relative exact simulation within a reasonable time. But for engineering purposes these models were often sufficient.

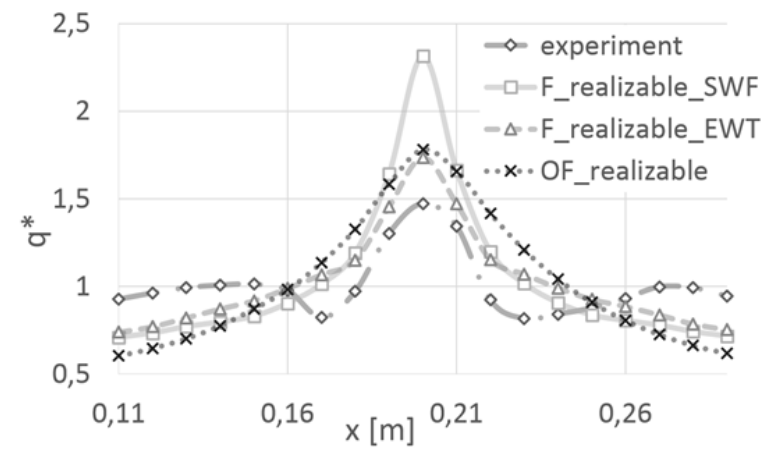

Fig. 14. Dimensionless heat flux for k-epsilon realizable model

The k-epsilon models generally smoothed the progress and overestimated heat flux. The dimensionless heat flux curves indicate the best match for the standard k-omega model in Ansys-Fluent. In OpenFOAM for all cases were the local minima smoothed out.

Regarding the total heat flux over the resolved space, the most accurate results is provided by the RNG modification of k-epsilon model with the enhanced wall treatment. But it is necessary to mention that a lot of information about the flow was smoothed out (the local minima) what could affect a similar based computation and distort significantly the results.

The computation times to solve the tasks are often very different for both platforms. This is partially given due to worse solution stability in OpenFOAM for more skewed meshes or more complex flow patterns for some solvers. As an example, it could be mentioned, that to obtain a similar solution for the same case OpenFOAM take 75 minutes while Fluent needed only 20 minutes. This is partially given by the time domain of both approaches. Fluent solves only statistically steady state (steady solution), while the OpenFOAM fully resolves all the time steps leading to statistically the steady state. 


\section{References}

1. M. Korger, F. Kořínek. Součinitele prenosu hmoty při impaktním prouděni ze štěrbinových trysek. Strojírenství (17), 536-541. [retrieved 2016-06-28]

2. S. Polat, Heat and Mass Transfer in Impingement Drying, (Drying Technology, 11, 1993)

3. H. Martin, B. Spalding, S. Whitaker, H. H. Winter, Advances in Heat Transfer, (v13, 1977)

4. S. M. Ghiaasiaan, Convective Heat and Mass Transfer, Georgia Institute of Technology, (2011)

5. M. Zogg, Wärme- und Stofftransportprozesse, (Otto Salle Verlag, Frnkfurt am Main,1983)

6. Kolár, Adámek, Evaporation and impact flows in $C F D$

7. J. Příhoda, P. Louda, Matematické modelování turbulentního proudění. (ČVUT, Praha, 2007)

8. Ch. J. Geankoplis. Transport Processes and Separation Process Principles. (Prentice hall, 2003)

9. ANSYS Fluent Theory Guide r.17.0, (2016) 